\title{
Structural and spectroscopic characterisation of bis[1-(diaminomethylene)thiouron-1-ium] fumarate
}

\author{
Jan Janczak $^{\mathrm{a}, *}$, Genivaldo Julio Perpétuo ${ }^{\mathrm{b}}$ \\ a Institute of Low Temperature and Structure Research, Polish Academy of Sciences, PO Box 1410, 50950 Wrocław, Poland \\ ${ }^{\mathrm{b}}$ Departamento de Física, Instituto de Ciências Exatas e Biológicas, Universidade Federal de Ouro Preto, 35400-000 Ouro Preto, MG, Brazil
}

\section{A R T I C L E I N F O}

\section{Article history:}

Received 3 November 2010

Accepted 30 November 2010

Available online 14 December 2010

\section{Keywords:}

Bis[1-(diaminomethylene)thiouron-1-ium]

fumarate

Crystal structure

Hydrogen bonds

Vibrational spectroscopy

\begin{abstract}
A B S T R A C T
The single crystals of bis[1-(diaminomethylene)thiouron-1-ium] fumarate were grown using a solution growth technique. The compound crystallises in the centrosymmetric $P 2_{1} / c$ space group of the monoclinic system. The conformation of the 1-(diaminomethylene)thiouron-1-ium cation is not strictly planar, but twisted. Both arms of the cation are oppositely rotated by $13.8(1)^{\circ}$ around the $\mathrm{C}-\mathrm{N}$ bonds involving the central $\mathrm{N}$ atom. The fumarate(2-) anion is also non-planar, both deprotonated carboxylate groups are oppositely turned in relation to the planar carbon chain. The arrangement of oppositely charged components, i.e. 1-(diaminomethylene)thiouron-1-ium cations and fumarate(2-) anions in the crystal is mainly determined by ionic and hydrogen-bonding interactions forming three-dimensional network. The compound was also characterised by the FT-IR and Raman spectroscopy. The characteristic bands of the $\mathrm{NH}_{2}, \mathrm{C}=\mathrm{S}$ and $\mathrm{COO}^{-}$groups as well as of $\mathrm{C}-\mathrm{N}-\mathrm{C}, \mathrm{N}-\mathrm{C}-\mathrm{N}, \mathrm{C}-\mathrm{COO}$ and $\mathrm{C}=\mathrm{C}-\mathrm{C}$ skeletal groups are discussed. The vibrational assignments have been supported by the isotropic frequency shift.
\end{abstract}

(c) 2010 Published by Elsevier B.V.

\section{Introduction}

Studies on the self-assembly of organic and inorganic molecules in the solid state have become intense research activity due to their physical and chemical properties as well as due to their applications in the field of material sciences, molecular biology, pharmaceutical sciences, supramolecular chemistry and the crystal engineering [1-5]. The directional interactions resulting from the multiple hydrogen bonds with the neighbours, mainly the $\mathrm{O}-\mathrm{H} \cdots \mathrm{O}, \mathrm{O}-\mathrm{H} \cdots \mathrm{N}$ and $\mathrm{N}-\mathrm{H} \cdots \mathrm{O}$ or $\mathrm{N}-\mathrm{H} \cdots \mathrm{N}$, play an important role in molecular recognition and self-assembly of organic or organic-inorganic molecules in solids [6-8]. Many different self-complementary hydrogen bonding groups can be used to control association in supramolecular chemistry to produce the programmed arrangement, such as chains, sheets, ribbons, tapes and rosettes [9-14].

One of the methods used for obtaining new materials is based on the acid-base ionic and directional hydrogen-bonding interactions and molecular recognition [15-17]. Some of the acid-base materials with ionic and hydrogen-bonding interactions exhibit non-linear optical properties [18-20]. In these materials the acid part of the molecular crystals is responsible for favourable chemical and physical properties due to the directional and strong hydro-

\footnotetext{
* Corresponding author.

E-mail address: j.janczak@int.pan.wroc.pl (J. Janczak).
}

gen bonds, while the base organic part with the relatively strong hyperpolarisability is mainly responsible for non-linear optical properties [21,22].

The crystalline 2-imino-4-thiobiuret (Aldrich, CAS No. 2114-0205 ) is in fact the tautomeric form of 1-(diaminomethylene)thiourea (Scheme 1) as has been identified by the X-ray single crystal analysis [23].

Both tautomers, i.e., 2-imino-4-thiobiuret and 1-(diaminomethylene)thiourea, are potentially interesting compounds as an organic base and can be used in the crystal engineering for obtaining base-acid materials with extended hydrogen bonds framework, since they contain several active hydrogen bonding sites (Scheme 1). Additionally, both tautomers can act as $\mathrm{N}, \mathrm{N}$ - or $\mathrm{N}, \mathrm{S}$-coordinating ligands forming several types of complexes with metal ions [2426]. Besides, the known Pt and Pd complexes with these tautomers, the 1-(diaminomethylene)thiourea or its 2-imino-4-thiobiuret tautomer can form salts, since they contain the basic $\mathrm{N}$ atom with the lone-pair of electrons that can accept the $\mathrm{H}^{+}$forming positively charged cations that together with the oppositely charged partners can form extended hydrogen bonded networks in solids [27-31]. In the present work, we investigate the crystal structure of 1-(diaminomethylene)thiouron-1-ium fumarate by the X-ray single crystal diffraction method. The compound was also characterised by vibrational spectroscopy, and the results are discussed and compared with the data obtained for a neutral 1-(diaminomethylene)thiourea molecule. 
<smiles>N/N=C(/N)NC(N)=S</smiles><smiles>NNC(N)=S</smiles>

Scheme 1.

\section{Experimental}

All materials were commercially available and used as received. Elemental analysis was carried out with a Perkin-Elmer 240 elemental analyzer.

\subsection{Preparation of bis[1-(diaminomethylene)thiouron-1-ium] fumarate}

Commercially available 2-imino-4-thiobiuret (amidinothiourea, Aldrich, CAS No. 2114-02-05), which is in fact the tautomeric form 1-(diaminomethylene)thiourea and fumaric acid (Aldrich, purity of $99 \%)$ were added to hot water in a molar proportion of $1: 1$. When the solution became homogenous it was cooled slowly and kept at room temperature. After several days, transparent colourless crystals were formed. Anal. Calculated for $\mathrm{C}_{8} \mathrm{H}_{16} \mathrm{~N}_{8} \mathrm{O}_{4} \mathrm{~S}_{2}$ : C, 27.28\%; $\mathrm{H}$, 4.54\%; N, 31.80\%; O, $18.19 \%$ and S, $18.19 \%$. Found: C. $27.33 \%$; $4.51 \%$; N, 31.82\%; O, $18.22 \%$ and S, $18.12 \%$.

\subsection{X-ray data collection}

X-ray intensity data for the crystal were collected using graphite monochromatic Mo K $\alpha$ radiation on a four-circle $\kappa$ geometry KUMA KM-4 diffractometer with a two-dimensional area CCD detector. The $\omega$-scan technique with $\Delta \omega=1.0^{\circ}$ for each image was used for data collection. The 760 images for six different runs covering over $99 \%$ of the Ewald sphere were performed. The unit cell parameters were refined by the least-squares methods on the basis of 1522 reflections. One image was used as a standard after every 40 images for monitoring of the crystal stability and data collection, and no correction on the relative intensity variations was necessary. 10190 reflections (2045 independent, $R_{\text {int }}=0.0210$ ) were measured up to $59.0^{\circ}$ in $2 \theta$. Data collections were made using the CrysAlis CCD program [32]. Integration, scaling of the reflections, correction for Lorenz and polarisation effects and absorption corrections were performed using the CrysAlis Red program [32]. The structure was solved by the direct methods using SHELXS-97 and refined using SHELXL-97 programs [33]. The hydrogen atoms were located in difference Fourier maps and were refined. The final difference Fourier maps showed no peaks of chemical significance. The largest peaks on the final $\Delta \rho$ map were +0.222 and -0.230 e $\AA^{-3}$. Details of the data collection parameters, crystallographic data and final agreement parameters are collected in Table 1. Visualisation of the structure was made with the Diamond 3.0 program [34]. Selected geometrical parameters are listed in Table 2 and the geometry of hydrogen-bonding interactions are collected in Table 3.

\subsection{Vibrational spectra measurements}

The vibrational measurements were carried out at room temperature. The Fourier transform infrared spectrum was recorded from nujol mulls between 4000 and $400 \mathrm{~cm}^{-1}$ on a Bruker IFS 113 V FT-IR. The Fourier Transform Raman spectrum was recorded on a FRA-106 attached to the Bruker $113 \mathrm{~V}$ FT-IR spectrometer equipped with Ge detector cooled to liquid nitrogen temperature.
Table 1

Crystallographic data for bis[1-(diaminomethylene)thiouron-1-ium] fumarate.

\begin{tabular}{|c|c|}
\hline Empirical formula & $\left(\mathrm{C}_{2} \mathrm{H}_{7} \mathrm{~N}_{4} \mathrm{~S}\right)_{2}\left(\mathrm{C}_{4} \mathrm{H}_{2} \mathrm{O}_{4}\right)$ \\
\hline Formula weight $\left(\mathrm{g} \mathrm{mol}^{-1}\right)$ & 352.38 \\
\hline Crystal system, space group & Monoclinic, $P 2_{1} / c$ (No. 14 ) \\
\hline$a(\AA)$ & $9.4229(19)$ \\
\hline$b(\AA)$ & $7.5791(15)$ \\
\hline$c(\AA)$ & $11.4021(21)$ \\
\hline$\beta\left(^{\circ}\right)$ & $114.33(1)$ \\
\hline$V\left(\AA^{3}\right)$ & $742.0(3)$ \\
\hline$Z$ & 2 \\
\hline$D_{\text {calc }} / D_{\text {obs }}\left(\mathrm{g} \mathrm{cm}^{-3}\right)$ & $1.577 / 1.57$ \\
\hline$\mu\left(\mathrm{mm}^{-1}\right)$ & 0.392 \\
\hline Crystal size (mm) & $0.32 \times 0.28 \times 0.23$ \\
\hline Radiation type, wavelength, $\lambda(\AA)$ & Mo K $\alpha, 0.71073$ \\
\hline Temperature (K) & $295(2)$ \\
\hline$\theta$ range $\left(^{\circ}\right)$ & $3.33-29.50$ \\
\hline Absorption correction & Numerical, CrysAlis Red [32] \\
\hline$T_{\min } / T_{\max }$ & $0.8849 / 0.9153$ \\
\hline Reflections collected/unique/observed & $10190 / 2045 / 1673$ \\
\hline$R_{\text {int }}$ & 0.0210 \\
\hline Refinement on & $F^{2}$ \\
\hline$R\left[F^{2}>2 \sigma\left(F^{2}\right)\right]$ & 0.0287 \\
\hline$w R$ ( $F^{2}$ all reflections) & 0.0728 \\
\hline Goodness-of-fit, $S$ & 1.004 \\
\hline$\Delta \rho_{\max }, \Delta \rho_{\min }\left(\mathrm{e} \AA^{-3}\right)$ & $+0.222,-0.2230$ \\
\hline
\end{tabular}

$w R=\left\{\sum\left[w\left(F_{o}^{2}-F_{c}^{2}\right)^{2}\right] / \sum w F_{o}^{4}\right\}^{1 / 2} ; w^{-1}=1 /\left[\sigma^{2}\left(F_{o}^{2}\right)+(0.0577 P)^{2}+0.1293 P\right]$ where $P=\left(F_{o}^{2}+2 F_{c}^{2}\right) / 3$.

Table 2

Bond lengths $(\AA)$ and angles $\left(^{\circ}\right)$ for bis[1-(diaminomethylene)thiouron-1-ium] fumarate.

\begin{tabular}{llll}
\hline $\mathrm{S} 1-\mathrm{C} 1$ & $1.6808(11)$ & $\mathrm{C} 1-\mathrm{N} 2$ & $1.3164(15)$ \\
\hline $\mathrm{C} 1-\mathrm{N} 1$ & $1.3833(14)$ & $\mathrm{N} 1-\mathrm{C} 2$ & $1.3594(14)$ \\
$\mathrm{C} 2-\mathrm{N} 4$ & $1.3151(15)$ & $\mathrm{C} 2-\mathrm{N} 3$ & $1.3178(15)$ \\
O1-C3 & $1.2573(14)$ & $\mathrm{O} 2-\mathrm{C} 3$ & $1.2523(14)$ \\
$\mathrm{C} 3-\mathrm{C} 4$ & $1.4953(15)$ & $\mathrm{C} 4-\mathrm{C} 4$ & $1.321(2)$ \\
$\mathrm{N} 2-\mathrm{C} 1-\mathrm{N} 1$ & $113.12(10)$ & $\mathrm{N} 2-\mathrm{C} 1-\mathrm{S} 1$ & $121.11(9)$ \\
N1-C1-S1 & $125.73(8)$ & $\mathrm{C} 2-\mathrm{N} 1-\mathrm{C} 1$ & $129.54(10)$ \\
N4-C2-N3 & $120.69(11)$ & $\mathrm{N} 4-\mathrm{C} 2-\mathrm{N} 1$ & $116.65(10)$ \\
N3-C2-N1 & $122.66(10)$ & $\mathrm{O} 2-\mathrm{C} 3-\mathrm{O} 1$ & $124.14(11)$ \\
O2-C3-C4 & $116.71(10)$ & $\mathrm{O} 1-\mathrm{C} 3-\mathrm{C} 4$ & $119.16(10)$ \\
$\mathrm{C} 3-\mathrm{C} 4-\mathrm{C} 4$ & $123.12(13)$ & & \\
\hline
\end{tabular}

Symmetry code, $i=-x,-y,-z+1$.

Table 3

Hydrogen-bond geometry $\left(\AA{ }^{\circ}\right)$.

\begin{tabular}{lllll}
\hline $\mathrm{D}-\mathrm{H} \cdots \mathrm{A}$ & $\mathrm{D}-\mathrm{H}$ & $\mathrm{H} \cdots \mathrm{A}$ & $\mathrm{D} \cdots \mathrm{A}$ & $\mathrm{D}-\mathrm{H} \cdots \mathrm{A}$ \\
\hline $\mathrm{N} 1-\mathrm{H} 1 \cdots \mathrm{O} 1$ & $0.854(15)$ & $1.863(15)$ & $2.7080(13)$ & $169.9(14)$ \\
$\mathrm{N} 2-\mathrm{H} 2 \cdots \mathrm{O} 1^{i}$ & $0.866(16)$ & $2.075(17)$ & $2.9394(17)$ & $176.0(15)$ \\
$\mathrm{N} 3-\mathrm{H} 4 \cdots \mathrm{O} 2^{i i}$ & $0.810(18)$ & $2.275(17)$ & $2.9430(18)$ & $140.2(15)$ \\
$\mathrm{N} 3-\mathrm{H} 5 \cdots \mathrm{S} 1$ & $0.858(19)$ & $2.310(20)$ & $3.0102(17)$ & $139.3(16)$ \\
$\mathrm{N} 4-\mathrm{H} 6 \cdots \mathrm{O} 2$ & $0.896(16)$ & $1.928(16)$ & $2.8214(15)$ & $175.1(13)$ \\
$\mathrm{N} 4-\mathrm{H} 7 \cdots \mathrm{O} 2^{i i}$ & $0.882(18)$ & $2.040(18)$ & $2.8550(16)$ & $153.0(16)$ \\
\hline
\end{tabular}

Symmetry code: $i=-x, y+1 / 2,-z+1 / 2 ; i i=-x+1, y+1 / 2,-z+1.5$.

Resolution was set up to $2 \mathrm{~cm}^{-1}$, signal/noise ratio was established by 32 scans. $\mathrm{Nd}^{3+}$-YAG air-cooled diode pumped laser of power ca. $200 \mathrm{~mW}$ was used as an exciting source. The incident laser excitation was $1064 \mathrm{~nm}$. The scattered light was collected at the angle of $180^{\circ}$ in the region of $3600-80 \mathrm{~cm}^{-1}$, resolution $2 \mathrm{~cm}^{-1}, 256$ scans. Deuterated $\mathrm{D}^{7}$ bis[1-(diaminomethylene)thiouron-1-ium] fumarate was prepared by the usual reaction with heavy water. The crystals of bis[1-(diaminomethylene)thiouron-1-ium] fumarate were dissolved in heavy water, and was left in the atmosphere saturated with heavy water for 2 weeks in order to avoid the contamination of the crystals. Than the procedure was repeated twice. The 
obtained deuterated analogue crystallizes similar as H-compound in monoclinic system $\left(P 2_{1} / c\right)$ with quite similar lattice parameters.

\section{Results and discussion}

Good quality single crystals of bis[1-(diaminomethylene)thiouron-1-ium] fumarate suitable for the X-ray analysis were obtained from water solution at room temperature. The X-ray single crystal analysis shows that both carboxyl groups of fumaric acid are deprotonated (Fig. 1). In addition, the X-ray analysis revealed that only a half of the deprotonated fumarate(2-) anion is independent, since it lies at the inversion center. The oppositely charged units, i.e. 1-(diaminomethylene)thiouron-1-ium cation and fumarate anion interact via two pairs of almost linear $\mathrm{N}-\mathrm{H} \ldots \mathrm{O}$ hydrogen bonds with a graph of $R_{2}^{2}(8)$ forming bis[1-(diaminomethylene)thiouron-1-ium] fumarate molecular complex (Fig. 2).

The 1-(diaminomethylene)thiouron-1-ium cation in the crystal is not strictly planar, but twisted. Both arms of the cation are oppositely rotated around the $\mathrm{C}-\mathrm{N}$ bonds involving the central $\mathrm{N} 1$ atom (Fig. 1). The dihedral angle between the N1/C1/S1/N2 and N1/C2/ $\mathrm{N} 3 / \mathrm{N} 4$ planes is $13.8(1)^{\circ}$. The rotation of the arms around the $\mathrm{C}-\mathrm{N}$ bonds in the present structure is significantly smaller than that in the crystal of neutral 1-(diaminomethylene)thiourea molecule $\left(22.2(1)^{\circ}\right)$ [23]. The contraction of the dihedral angle between the arms of the cation is undoubtedly connected with the electronic structure of the 1-(diaminomethylene)thiouron-1-ium cation, especially with the lone-pairs of electrons on the S1 atoms. Protonation of the 1-(diaminomethylene)thiourea molecule causes a decrease of the steric effect of the lone-pairs of electrons at the S1 atom, and in result reduces the dihedral angle between the arms of the cation. The $\mathrm{C} 1-\mathrm{S} 1$ bond (Table 2 ) is slightly longer than the typical $\mathrm{C}=\mathrm{S}$ double bond as observed in the thioformaldehyde $\mathrm{CH}_{2} \mathrm{C}=\mathrm{S}(1.6019(8) \AA)$ [35], which represents $100 \%$ double-bond character, and is slightly shorter than the value of $\sim 1.74 \AA$ as observed in several thiolate anions that represents 50\% double-bond character [36]. Thus the bond order of the $\mathrm{C} 1-\mathrm{S} 1$ bond is intermediate between the 2 and 1.5. The three $\mathrm{C}-\mathrm{NH}_{2}$ bond distances are in the range of $1.315(2)-1.319(2) \AA$, are thus shorter than typical single bond $\mathrm{C}\left(\mathrm{sp}^{2}\right)-\mathrm{NH}_{2}$ of $1.341-1.363 \AA$ [37]. The central $\mathrm{N} 1$ atom links both arms of the 1-(diaminomethylene)thiouron-1ium cation by a shorter bond to atom C2 (1.359(2) $\AA$ ) and a longer bond to atom $\mathrm{C} 1$ (1.383(2) $\mathrm{A})$. However, both $\mathrm{C}-\mathrm{N}$ bonds involving the central $\mathrm{N} 1$ atom are significantly longer than the three $\mathrm{C}-\mathrm{NH}_{2}$ bonds linking the amine groups (Table 2). The planarity of the amine groups points to the $\mathrm{sp}^{2}$ hybridisation of the orbitals on the amine nitrogen atoms. This indicates that the lone-pair of electrons occupies the $\mathrm{p}$ orbital that is perpendicular to the plane of $\mathrm{NH}_{2}$ group. Additionally, the p orbitals of the $\mathrm{C}, \mathrm{S}$ and $\mathrm{N}$ atoms

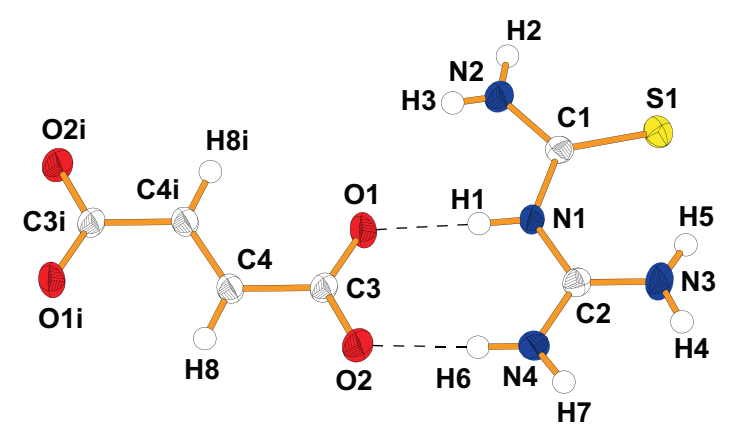

Fig. 1. A view of bis[1-(diaminomethylene)thiouron-1-ium] fumarate showing displacement ellipsoids at the $50 \%$ probability level and $\mathrm{H}$ atoms as a sphere of arbitrary radii. Dashed lines represent the hydrogen bonds. Symmetry code: $i=-\chi$, $-y, 1-z$.

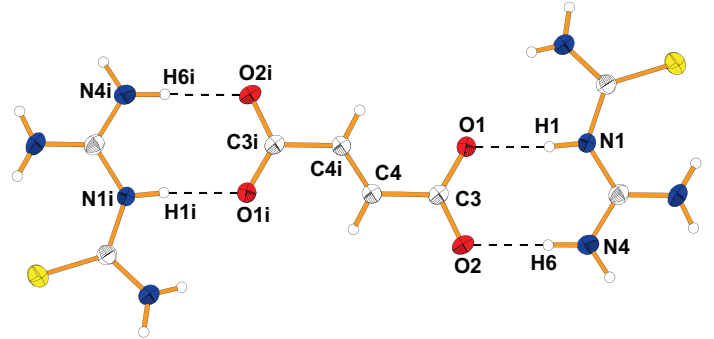

Fig. 2. A view of hydrogen bonded bis[1-(diaminomethylene)thiouron-1-ium] fumarate molecular complex. Symmetry code: $i=-x,-y, 1-z$.

forming the $\pi$ bond of the $\mathrm{C} 1-\mathrm{S} 1$ and $\mathrm{C} 2-\mathrm{N} 1$ double bonds as observed in neutral molecule (see Scheme 1) are also perpendicular to the plane. Therefore due to symmetry of the $\mathrm{p}$ orbitals the par-

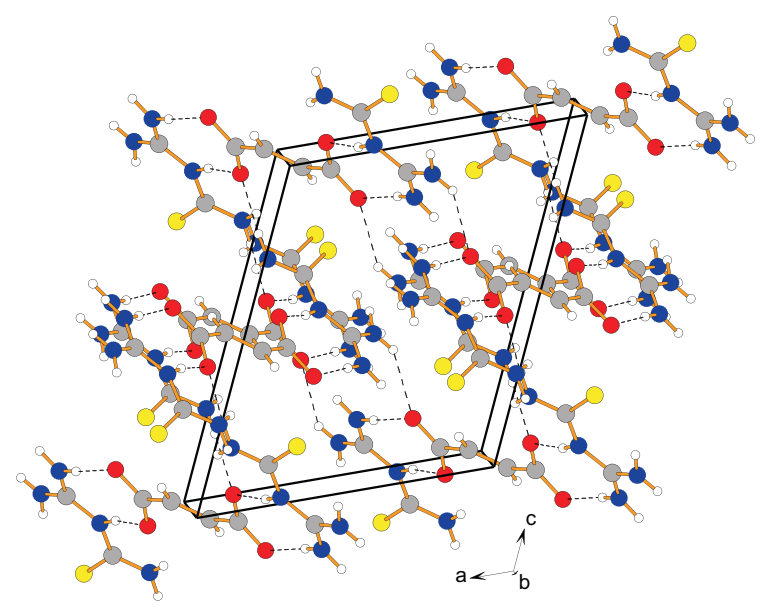

Fig. 3. Molecular packing of bis[1-(diaminomethylene)thiouron-1-ium] fumarate in the unit cell.

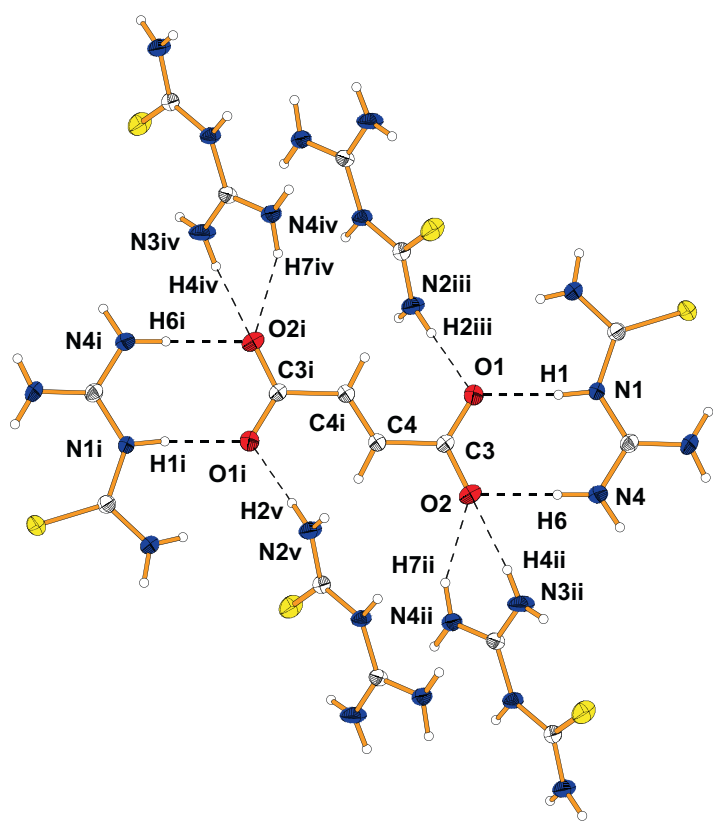

Fig. 4. A view of hydrogen-bonding interaction of bis[1-(diaminomethylene)thiouron-1-ium] fumarate molecular complex with the neighbours. Symmetry code: $i=-x,-y, 1-z ; i i=1-x,-0.5+y, 1.5-z ; i i i=-x,-0.5+y,-0.5+z ; i v=-1+x$, $0.5+y,-0.5+z ; v=x, 0.5-y, 0.5+z$. 

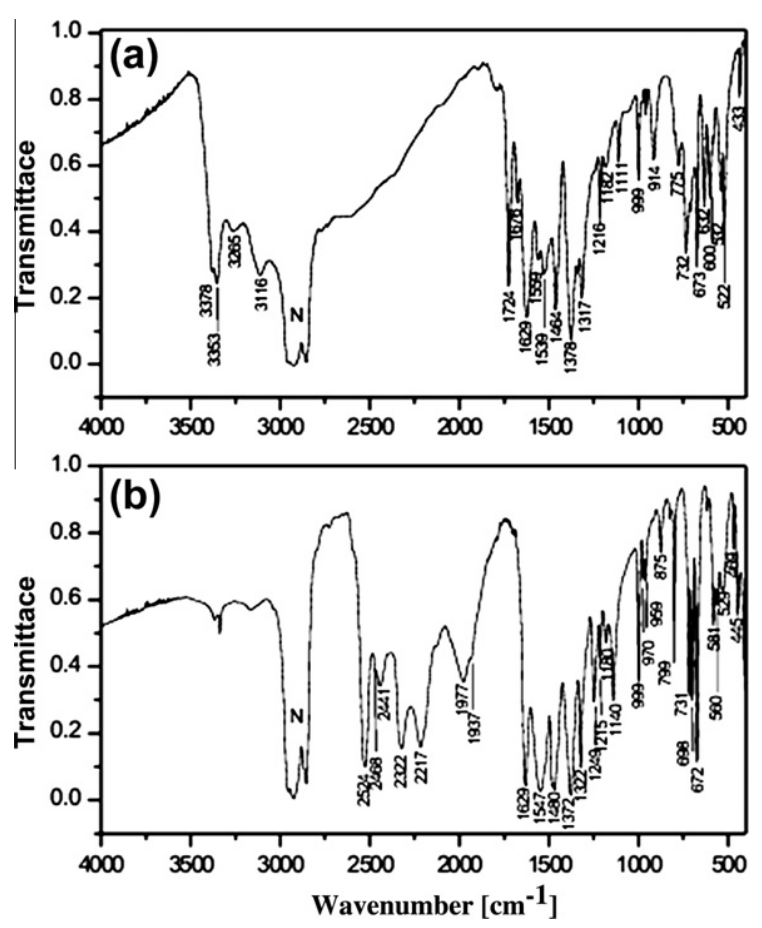

Fig. 5. Room temperature FT-IR spectrum of bis[1-(diaminomethylene)thiouron-1ium] fumarate (a) and its deuterated analogue (b).

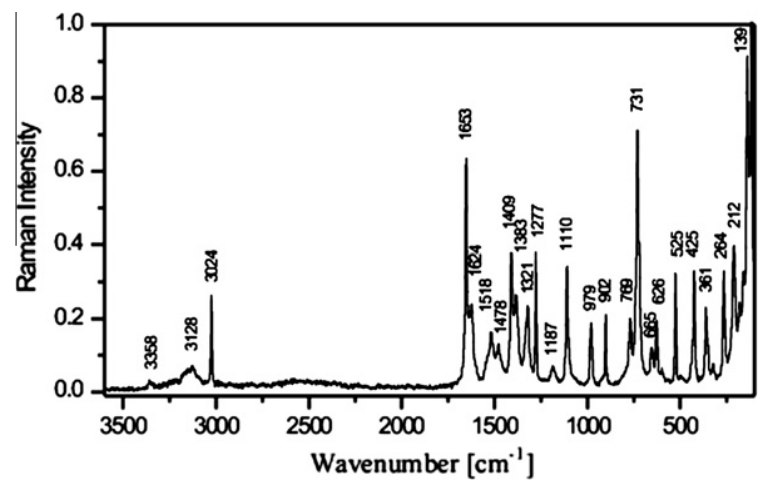

Fig. 6. Raman spectrum of bis[1-(diaminomethylene)thiouron-1-ium] fumarate.

tial delocalisation of $\pi$ bonds is possible and leads to the elongation of the double $\mathrm{C} 1=\mathrm{S} 1$ and $\mathrm{C} 2=\mathrm{N} 1$ bonds and to shortening of other $\mathrm{C}-\mathrm{N}$ bonds linking the amine groups (Table 2). Thus the bond order of the $\mathrm{C}-\mathrm{NH}_{2}$ bonds is greater than of the both $\mathrm{C}-\mathrm{N}$ bonds involving the central $\mathrm{N} 1$ atom.

The centrosymmetric fumarate(2-) anion also exhibits twisted conformation as both $\mathrm{COO}^{-}$groups are turned oppositely by $13.7(1)^{\circ}$ in relation to the carbon chain. This is in contrast to the neutral fumaric acid molecule that in the crystal is almost planar $[38,39]$. In several structures of singly deprotonated fumarate(-) salts, the non-dissociated $\mathrm{COOH}$ group is coplanar with the carbon chain, while the deprotonated $\mathrm{COO}^{-}$group is turned around the $C-C$ bond by an angle between 5.1(1) and 30.3(1) $[40,41]$. Similarly as in the present structure, in several structures of double deprotonated fumarate(2-) salts, the $\mathrm{COO}^{-}$groups are oppositely turned in relation to the planar carbon chain, however the rotation angle varied between the $\pm 2.4(1)^{\circ}$ in calcium fumarate trihydrate [42] to $\pm 23.69(5)^{\circ}$ in $N, N^{\prime}$-bis-(pyridyl)urea fumarate [43]. Thus deprotonation of the carboxyl groups in the fumaric acid leads to the twisted conformation, but the rotation angle depends on the
Table 4

FT-IR and Raman spectral data for bis[1-(diaminomethylene)thiouron-1-ium] fumarate.

\begin{tabular}{|c|c|c|}
\hline $\begin{array}{l}\text { Infrared, } v \\
\left(\mathrm{~cm}^{-1}\right)\end{array}$ & $\begin{array}{l}\text { Raman, } v \\
\left(\mathrm{~cm}^{-1}\right)\end{array}$ & Assignment \\
\hline $3378 \mathrm{~m}$ & & $v_{\mathrm{a}}\left(\mathrm{NH}_{2}\right)$ asym stretch \\
\hline $3353 \mathrm{~m}$ & 3358w & $v_{\mathrm{a}}\left(\mathrm{NH}_{2}\right)$ asym stretch \\
\hline $3265 w$ & $3128 w$ & $v_{\mathrm{s}}\left(\mathrm{NH}_{2}\right)$ sym stretch \\
\hline $3116 w$ & $3024 \mathrm{~m}$ & $v_{\mathrm{s}}\left(\mathrm{NH}_{2}\right)$ sym stretch \\
\hline \multicolumn{3}{|l|}{$\sim 2700$} \\
\hline $1724 s$ & & Imine bond stretch \\
\hline $1676 \mathrm{~m}$ & $1653 s$ & $v(\mathrm{C}=\mathrm{C})$ \\
\hline $1629 s$ & $1624 \mathrm{~m}$ & $v_{\mathrm{a}}\left(\mathrm{CO}_{2}^{-}\right)$ \\
\hline \multicolumn{3}{|l|}{$1559 \mathrm{~m}$} \\
\hline \multirow[t]{2}{*}{$1529 m$} & $1518 w$ & $\begin{array}{l}v(\mathrm{C}-\mathrm{N}) \text { overlapped with } \delta\left(\mathrm{NH}_{2}\right) \text { asym } \\
\text { def. }\end{array}$ \\
\hline & 1478w & $v(\mathrm{C}-\mathrm{N})$ \\
\hline \multirow[t]{2}{*}{$1464 s$} & & $\gamma(C-C)$ overlapped with nujol \\
\hline & $1409 \mathrm{~m}$ & \\
\hline $1378 v s$ & $1383 \mathrm{~m}$ & $v_{\mathrm{s}}\left(\mathrm{CO}_{2}^{-}\right)$overlapped with nujol \\
\hline \multirow{2}{*}{$1317 \mathrm{~s}$} & $1321 \mathrm{~m}$ & $\delta\left(\mathrm{NH}_{2}\right)$ \\
\hline & $1277 \mathrm{~m}$ & $\delta\left(\mathrm{NH}_{2}\right)$ \\
\hline $1216 \mathrm{~m}$ & & $v(\mathrm{C}-\mathrm{N})$ \\
\hline $1182 w$ & $1187 w$ & $v(\mathrm{C}-\mathrm{C})$ \\
\hline $1111 \mathrm{~m}$ & $1110 \mathrm{~m}$ & $\gamma\left(\mathrm{NH}_{2}\right)$ \\
\hline \multirow[t]{2}{*}{$999 m$} & & $\gamma(\mathrm{C}-\mathrm{H})$ \\
\hline & $979 m$ & $\gamma(\mathrm{C}-\mathrm{H})$ \\
\hline \multirow[t]{2}{*}{$914 \mathrm{~m}$} & $902 \mathrm{~m}$ & $\gamma(\mathrm{C}-\mathrm{N})$ \\
\hline & & $\gamma(C-C)$ \\
\hline $775 \mathrm{~m}$ & $769 \mathrm{~m}$ & $\gamma(\mathrm{C}-\mathrm{C})$ \\
\hline $734 \mathrm{~s}$ & $731 \mathrm{vs}$ & $v(\mathrm{C}=\mathrm{S})$ \\
\hline $673 s$ & $665 w$ & Skeletal $\mathrm{C}-\mathrm{N}-\mathrm{C}, \mathrm{N}-\mathrm{C}-\mathrm{N}, \mathrm{C}-\mathrm{C}-\mathrm{C}$ \\
\hline $632 \mathrm{~m}$ & $626 \mathrm{~m}$ & $\tau\left(\mathrm{NH}_{2}\right), \omega\left(\mathrm{NH}_{2}\right)$ \\
\hline $600 \mathrm{~m}$ & & Skeletal $\mathrm{C}-\mathrm{N}-\mathrm{C}, \mathrm{N}-\mathrm{C}-\mathrm{N}, \mathrm{C}-\mathrm{C}-\mathrm{C}$ \\
\hline $532 \mathrm{~m}$ & & Skeletal $\mathrm{C}-\mathrm{N}-\mathrm{C}, \mathrm{N}-\mathrm{C}-\mathrm{N}, \mathrm{C}-\mathrm{C}-\mathrm{C}$ \\
\hline $522 \mathrm{~s}$ & $525 m$ & $\delta(\mathrm{C}-\mathrm{COO})$ \\
\hline \multirow[t]{5}{*}{$433 w$} & $425 \mathrm{~m}$ & $\gamma(\mathrm{C}-\mathrm{COO})$ \\
\hline & $361 \mathrm{~m}$ & $\delta(\mathrm{CS})$ \\
\hline & $264 m$ & Skeletal \\
\hline & $212 \mathrm{~m}$ & \\
\hline & $139 s$ & \\
\hline
\end{tabular}

geometry and the structure of the cationic partners of the crystals. The almost equal $\mathrm{C}-\mathrm{O}$ distances of the $\mathrm{COO}^{-}$point to the delocalisation of the charge over both $\mathrm{C}-\mathrm{O}$ bonds. The single $\mathrm{C} 3-\mathrm{C} 4$ bond is slightly shorter than a typical $\mathrm{C}-\mathrm{C}$ single bond and the double $\mathrm{C} 4-\mathrm{C} 4^{i}$ is slightly longer than the typical double $\mathrm{C}=\mathrm{C}$ bond [37]. The values of the $\mathrm{C}-\mathrm{C}$ bond distances in the carbon chain together with the $\mathrm{sp}^{2}$ hybridisation of the orbitals on the all carbon atoms indicate a partial delocalisation of the $\pi$ bond over the whole carbon skeleton.

The oppositely charged units, i.e., 1-(diaminomethylene)thiouron-1-ium cation and fumarate anion interact via two pairs of almost linear $\mathrm{N}-\mathrm{H} \cdots \mathrm{O}$ hydrogen bonds with a graph of $R_{2}^{2}(8)$ forming in the crystal the bis[1-(diaminomethylene)thiouron-1ium] fumarate molecular complex (Fig. 3). The center of the $\mathrm{C} 4-\mathrm{C} 4^{i}$ bond of the molecular complex lies at the inversion center. The bis[1-(diaminomethylene)thiouron-1-ium] fumarate molecular complex interacts with the neighbours via $\mathrm{N}-\mathrm{H} \cdots \mathrm{O}$ hydrogen bonds (see Fig. 4) forming a three-dimensional hydrogen bonded network (Fig. 3).

The FT-IR spectra of bis[1-(diaminomethylene)thiouron-1-ium] fumarate and its deuterated analogue are shown in Fig. 5a and b, respectively, while the Raman spectrum for protiated complex is given in Fig. 6. The bands corresponding to the vibration of the functional groups were identified with the aid of infrared correlation charts $[44,45]$. In addition, the spectra of bis[1-(diaminomethylene)thiouron-1-ium] fumarate are compared with the spectra of 1-(diaminomethylene)thiourea [46] and of fumaric acid [47,48]. The title compound has several functional and skeletal groups such 
Table 5

FT-IR spectral data for deuterated bis[1-(diaminomethylene)thiouron-1-ium] fumarate.

\begin{tabular}{|c|c|}
\hline Infrared, $v\left(\mathrm{~cm}^{-1}\right)$ & Assignment \\
\hline $2524 s$ & $\mathrm{ND}_{2}$ asym stretch \\
\hline $2468 \mathrm{~m}$ & $\mathrm{ND}_{2}$ asym stretch \\
\hline $2441 \mathrm{~m}$ & $\mathrm{ND}_{2}$ sym stretch \\
\hline $2322 \mathrm{~m}$ & $\mathrm{ND}_{2}$ sym stretch \\
\hline $2217 \mathrm{~m}$ & $\mathrm{ND}_{2}$ sym stretch \\
\hline $1977 \mathrm{~m}$ & $\mathrm{~N}-\mathrm{D} \cdots \mathrm{O}$ \\
\hline $1937 \mathrm{~m}$ & $\mathrm{~N}-\mathrm{D} \cdots \mathrm{O}$ \\
\hline $1629 s$ & $v_{\mathrm{a}}\left(\mathrm{CO}_{2}^{-}\right)$ \\
\hline \multicolumn{2}{|l|}{$1547 s$} \\
\hline $1480 \mathrm{~s}$ & $v(\mathrm{C}-\mathrm{N}), v(\mathrm{C}-\mathrm{C})$ overlapped with nujol \\
\hline $1372 s$ & $v_{\mathrm{s}}\left(\mathrm{CO}_{2}^{-}\right)$overlapped with nujol \\
\hline \multicolumn{2}{|r|}{ 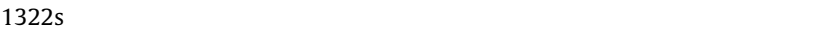 } \\
\hline $1249 m$ & Imine bond stretch (ND) \\
\hline $1215 \mathrm{~m}$ & $v(\mathrm{C}-\mathrm{N})$ \\
\hline $1180 w$ & $v(\mathrm{C}-\mathrm{C})$ \\
\hline \multicolumn{2}{|l|}{$1140 \mathrm{~m}$} \\
\hline $999 m$ & $\delta(\mathrm{C}-\mathrm{H})$ \\
\hline 970m & $\delta(\mathrm{C}-\mathrm{H})$ overlapped with $\mathrm{ND}_{2}$ rocking \\
\hline $959 \mathrm{~m}$ & $v(\mathrm{C}-\mathrm{N}), \delta\left(\mathrm{ND}_{2}\right)$ \\
\hline $875 w$ & $v(\mathrm{C}-\mathrm{C})$ \\
\hline $825 w$ & $\gamma\left(\mathrm{ND}_{2}\right)$ \\
\hline 799m & $\mathrm{C}-\mathrm{C}$ stretch \\
\hline $731 \mathrm{~s}$ & $v(\mathrm{C}=\mathrm{S})$ \\
\hline $698 s$ & Skeletal $\mathrm{C}-\mathrm{N}-\mathrm{C}, \mathrm{N}-\mathrm{C}-\mathrm{N}, \mathrm{C}-\mathrm{C}-\mathrm{C}$ \\
\hline $672 \mathrm{~m}$ & Skeletal $\mathrm{C}-\mathrm{N}-\mathrm{C}, \mathrm{N}-\mathrm{C}-\mathrm{N}, \mathrm{C}-\mathrm{C}-\mathrm{C}$ \\
\hline $581 \mathrm{~m}$ & Skeletal $\mathrm{C}-\mathrm{N}-\mathrm{C}, \mathrm{N}-\mathrm{C}-\mathrm{N}, \mathrm{C}-\mathrm{C}-\mathrm{C}$ \\
\hline $560 \mathrm{~m}$ & Skeletal $\mathrm{C}-\mathrm{N}-\mathrm{C}, \mathrm{N}-\mathrm{C}-\mathrm{N}, \mathrm{C}-\mathrm{C}-\mathrm{C}$ \\
\hline $529 s$ & $\delta(\mathrm{C}-\mathrm{COO})$ \\
\hline $469 w$ & $\gamma(\mathrm{C}-\mathrm{COO})$ overlapped with $\tau\left(\mathrm{NH}_{2}\right), \omega\left(\mathrm{NH}_{2}\right)$ \\
\hline $445 \mathrm{~m}$ & $\tau\left(\mathrm{ND}_{2}\right), \omega\left(\mathrm{ND}_{2}\right)$ \\
\hline
\end{tabular}

as three $\mathrm{NH}_{2}, \mathrm{C}=\mathrm{S}, \mathrm{C}-\mathrm{N}-\mathrm{C}, \mathrm{N}-\mathrm{C}-\mathrm{N}$ and $\mathrm{N}-\mathrm{C}-\mathrm{S}$ groups in the cation and $\mathrm{COO}^{-}, \mathrm{C}-\mathrm{C}, \mathrm{C}-\mathrm{COO}^{-}, \mathrm{C}-\mathrm{C}-\mathrm{C}$ and $\mathrm{C}-\mathrm{H}$ in the anion. $\mathrm{A}$ careful inspection of the IR spectrum (Fig. 5a) shows mediumstrong intensity bands at 3378 and $3353 \mathrm{~cm}^{-1}$ and the weaker bands at 3265 and $3116 \mathrm{~cm}^{-1}$ that can be attributed to the asymmetric and symmetric stretching of $\mathrm{NH}_{2}$ groups of the 1-(diaminomethylene)thiouron-1-ium cation. These bands, as expected, are shifted in the IR spectrum of deuterated analogue (Fig. 5b) to the spectral region of $2532-2217 \mathrm{~cm}^{-1}$. The strong narrow band at $1724 \mathrm{~cm}^{-1}$ is assigned to the stretching of imine bond of the cation, since a similar band is observed in some imines and their slats [49]. In addition, the band of immine group of the deuterated analogue is shifted, as expected, to the $1249 \mathrm{~cm}^{-1}$ (Fig. 5b). The X-ray data reveal that the all $\mathrm{NH}_{2}$ groups of 1-(diaminomethylene)thiouron-1-ium cation are involved in the $\mathrm{N}-\mathrm{H} \ldots \mathrm{O}$ hydrogen bonds with N...O distances ranging from 2.708 to $2.943 \AA$. This reveals as a broad band in the range of $3300-2500 \mathrm{~cm}^{-1}$, which is shifted to $\sim 1950 \mathrm{~cm}^{-1}$ in the spectrum of deuterated analogue. Additionally, the broad band in the region of $1400-1100 \mathrm{~cm}^{-1}$ that overlaps with $v(\mathrm{C}-\mathrm{N})$ of the cation points the presence of the $\mathrm{N}-\mathrm{H} \cdots \mathrm{O}$ hydrogen bonds. The strong band at $1653 \mathrm{~cm}^{-1}$ in the Raman spectrum (Fig. 6) can be assigned to $v(\mathrm{C}=\mathrm{C})$ of fumarate anion, since a similar band is observed in the Raman spectrum of fumaric acid [47]. The $v_{\mathrm{a}}\left(\mathrm{CO}_{2}^{-}\right)$and $v_{\mathrm{s}}\left(\mathrm{CO}_{2}^{-}\right)$bands of fumarate anion in the IR spectrum of bis[1-(diaminomethylene)thiouron-1-ium] fumarate is observed at 1559 and $1378 \mathrm{~cm}^{-1}$, respectively, which are also present in other fumarate salts [50-53]. The band at $999 \mathrm{~cm}^{-1}$ in the IR spectrum of bis[1-(diaminomethylene)thiouron-1-ium] fumarate, observed also in the spectrum of its deuterated analogue, is assigned to $\delta(\mathrm{C}-\mathrm{H})$ of fumarate anion, since after deuteration the $\mathrm{H}$ atoms of the $\mathrm{C}-\mathrm{H}$ groups are unchanged. The $v(\mathrm{C}=\mathrm{S})$ band of the 1-(diaminomethylene)thiouron-1-ium cation, similar as in thiourea, is observed at $\sim 730 \mathrm{~cm}^{-1}$, while in several thiourea metal complexes the $v(\mathrm{C}=\mathrm{S})$ band is observed in the range $715-700 \mathrm{~cm}^{-1}$
[54]. The observed frequencies of the most prominent bands and their assignments are listed in Tables 4 and 5.

\section{Conclusion}

The single crystals of bis[1-(diaminomethylene)thiouron-1ium] fumarate were grown using a solution growth technique. The oppositely charged units of the crystal, i.e. 1-(diamino-methylene)thiouron-1-ium cation and fumarate dianion are not planar, they exhibit twisted conformation. The arrangement of these oppositely charged units in the crystal is mainly determined by the ionic and the $\mathrm{N}-\mathrm{H} \cdots \mathrm{O}$ hydrogen bonds forming three-dimensional network. Comparison of the IR spectra of bis[1-(diaminomethylene)thiouron-1-ium] fumarate and its deuterated analogue clearly shows marked differences in the regions of vibrations of the amine and imine groups as well as in the region of the $\mathrm{N}-\mathrm{H} \cdots \mathrm{O}$ hydrogen bonds.

\section{Appendix A. Supplementary material}

Additional material comprising full details of the X-ray data collection and final refinement parameters including anisotropic thermal parameters and full list of the bond lengths and angles have been deposited with the Cambridge Crystallographic Data Center in the CIF format as supplementary Publications No. CCDC 798711. Copies of the data can be obtained free of charge on the application to CCDC, 12 Union Road, Cambridge, CB21EZ, UK (fax: (+44) 1223336 033; email: deposit@ccdc.cam.ac.uk). Supplementary data associated with this article can be found, in the online version, at doi:10.1016/j.molstruc.2010.11.075.

\section{References}

[1] A. Nangia, Curr. Opin. Solid State Mater. Sci. 5 (2001) 115.

[2] J.C. MacDonald, G.R. Whitesides, Chem. Rev. 94 (1994) 2382.

[3] G.R. Desiraju, T. Steiner, The Weak Hydrogen Bond in Structural Chemistry and Biology, Oxford University Press, Oxford, 1999.

[4] A.D. Burrows, C.W. Chann, M.M. Chowdhy, J.E. McGrady, D.M.P. Mingos, Chem. Soc. Rev. 24 (1995) 329.

[5] M. Moulton, M. Zaworotko, Chem. Rev. 101 (2001) 1629.

[6] G.R. Desiraju, Acc. Chem. Res. 35 (2002) 565.

[7] T. Steiner, Angew. Chem., Int. Ed. Engl. 41 (2002) 48.

[8] G.M. Whitesides, E.E. Simanek, J.P. Mathias, C.T. Seto, D.N. Chin, M. Mammen, D.M. Gordon, Acc. Chem. Res. 28 (1995) 37.

[9] M.C.T. Fyfe, J.F. Stoddart, Acc. Chem. Res. 30 (1997) 393

[10] A.G. Bielejewska, C.E. Marjo, L.J. Prins, P. Timmerman, F. De Jong, D.N. Reinhoudt, J. Am. Chem. Soc. 123 (2001) 7518.

[11] S. Yagai, T. Nakajima, K. Kishikawa, S. Kohmoto, T. Karatsu, A. Kitamura, J. Am. Chem. Soc. 127 (2005) 11134.

[12] N. Sakai, Y. Kamikawa, M. Nishii, T. Matsuoka, T. Kato, S. Matile, J. Am. Chem. Soc. 128 (2006) 2218.

[13] C. Valles, C. Drummond, H. Saadaoui, C.A. Furado, M. He, O. Roubeau, L. Ortolani, M. Monthioux, A. Penicaud, J. Am. Chem. Soc. 130 (2008) 15802.

[14] X. Zhu, X.G. Liu, B.L. Li, Y. Zhang, CrystEngComm 11 (2009) 997.

[15] J. Janczak, G.J. Perpétuo, Solid State Sci. 11 (2009) 1576.

[16] J.M. Lehn, Proc. Indian Acad. Sci. (Chem. Sci.) 106 (1994) 915.

[17] T. Głowiak, S. Debrus, M. May, A.J. Barnes, H. Ratajczak, J. Mol. Struct. 596 (2001) 77.

[18] M. Marchewka, J. Janczak, S. Debrus, J. Baran, H. Ratajczak, Solid State Sci. 5 (2003) 643.

[19] G.J. Perpétuo, J. Janczak, Acta Crystallogr. C62 (2006) 0372.

[20] R.G. Xiang, C.M. Liu, G.L. Da, W. Hong, X.Z. You, Polyhedron 16 (1997) 1263.

[21] N. Blagden, K.R. Seddon, Cryst. Eng. 2 (1999) 9.

[22] S. Ghattacharya, P. Dastidar, T.N.G. Row, Chem. Mater. 6 (1994) 531.

[23] J. Janczak, G.J. Perpétuo, Acta Crystallogr. C64 (2008) 0114.

[24] K. Chakrabarty, T. Kar, S.P.S. Gupta, Acta Crystallogr. C46 (1990) 2065.

[25] M.K. Kabir, K. Yamada, K. Adachi, M. Kondo, S. Kawata, Acta Crystallogr. C58 (2002) m580.

[26] E. Doxiadi, R. Vilar, A.J.P. White, D.J. Williams, Polyhedron 22 (2003) 2991.

[27] G.J. Perpétuo, J. Janczak, Acta Crystallogr. C64 (2008) o264.

[28] J. Janczak, G.J. Perpétuo, Acta Crystallogr. C64 (2008) 0330.

[29] J. Janczak, G.J. Perpétuo, Acta Crystallogr. C65 (2009) 0118.

[30] M. Hołyńska, M. Kubiak, Acta Crystallogr. C64 (2008) 0609.

[31] M. Hołyńska, M. Kubiak, Acta Crystallogr. C65 (2009) 0191. 
[32] CrysAlis CCD and CrysAlis Red, Version 171.32.8, Oxford Diffraction Poland, Wrocław, Poland, 2006.

[33] G.M. Sheldrick, SHELXS97, SHELXL97, Programs for Crystal Structures Solution and Refinement, University of Göttingen, Göttingen, Germany, 1997.

[34] K. Brandenburg, H. Putz, DIAMOND Version 3.0, Crystal Impact GbR, Bonn, Germany, 2006.

[35] D.R. Johnson, F.X. Powell, W.H. Kirchoff, J. Mol. Spectrosc. 39 (1971) 136.

[36] R. Fausto, L.A.E. Batista de Carvalho, J.J.C. Teixeria-Dias, M.N. Ramos, J. Chem. Soc. Perkin Trans. 2 (1989) 1945

[37] F.H. Allen, O. Kennard, D.G. Watson, L. Brammer, A.G. Orpen, R. Taylor, J. Chem. Soc. Perkin Trans. 2 (1989) S1-S19.

[38] C.J. Brown, Acta Crystallogr. 21 (1966) 1

[39] A.L. Bednowitz, B. Post, Acta Crystallogr. 21 (1966) 566.

[40] K.A. Wichmann, P.D.W. Boyd, T. Söhnel, G.R. Allen, A.R.J. Phillips, G.J.S. Cooper, Cryst. Growth Des. 7 (2007) 1844.

[41] X.J. Cao, C.R. Sunm, Y.J. Pan, Acta Crystallogr. E60 (2004) 01546.
42] M.P. Gupta, S.M. Prasad, R.G. Sahu, B.N. Sahu, Acta Cryst. B28 (1972) 135

[43] N.N. Adarsh, D.K. Kumar, P. Dastidar, Tetrahedron 63 (2007) 7386.

[44] G. Socrates, Infrared Characteristic Group Frequencies, Wiley-Interscience, Chichester, UK, 1980.

[45] G. Socrates, Infrared and Raman Characteristic Group Frequencies, third ed. Wiley, New York, USA, 2001

[46] J. Janczak, G.J. Perpétuo, J. Mol. Struct. 975 (2010) 166.

[47] J. Maillols, L. Bardet, L. Maury, J. Mol. Struct. 30 (1976) 57.

[48] K.D. Dobson, A.J. McQuillan, Spectrochim. Acta A 55 (1999) 1395

[49] J. Favrot, D. Vocelle, C. Sandrofy, Photochem. Photobiol. 28 (1979) 417.

[50] W.H. Zhu, Z. M Wang, S. Gao, Dalton Trans. (2006) 765.

[51] F. Cataldo, Croat. Chim. Acta 73 (2000) 435.

[52] L. Huang, L.P. Zhang, J. Mol. Struct. 692 (2004) 249.

[53] M. Padmanabhan, J.C. Joseph, X. Huang, J. Li, J. Mol. Struct. 885 (2008) 36.

[54] F.H. Allen, C.H. Bird, R.S. Rowland, P.R. Raithby, Acta Crystallogr. B53 (1997) 680. 